\title{
Психологические теории группового поведения и их применимость для объяснения стадного поведения на финансовых рынках
}

\author{
Чиркова Е.B. ${ }^{25}$
}

В статье прослеживается развитие научного направления, называющегося «психологией толпьл", и обсуждается возможность применимости идей, разработанных в его рамках, для объяснения феномена стадного поведения на финансовых рынках. Данная статья является первой из серии статей, посвященных теоретическим обоснованиям финансовых пузырей.

JEL: $G 10$

Ключевые слова: стадное поведение, психология масс, финансовый рынок, финансовая мания

На рубеже XIX-XX веков европейские философы и психологи начинают заниматься новым научным направлением - психологией толпы. Основная идея ранних представителей этого течения заключается в том, что толпа стоит ниже по интеллекту и морали, чем индивидуум: «безумие - это исключение для индивидуумов, но правило для групп» (Фридрих Ницше); «я не верю в коллективную мудрость индивидуальных невежеств» (Томас Карлайл). Пионерами этого научного направления считаются французы - Гюстав ле Бон с его книгой «Психология народов и масс» (1895) и Габриэль Тард - автор «Мнения толпы» $(1901)^{26}$.

В 1878-1884 годах французский историк Ипполит Тайн публикует многотомный труд «Происхождение современного французского государства» («Les Origin de la France Contemporaine»), несколько томов которого посвящены Французской революции 1789 года. По мнению Тайна, революция представляла собой распад власти и общества, она вылилась в спонтанную анархию и власть толпы и на улицах, и в парламенте. Тайн анализирует психологическое состояние народа до и во время революции и приходит к выводу: «разъяренное животное уничтожает все на своем пути, пусть даже ценой собственных ранений, с ревом устремляясь к препятствию, которое должно быть устранено. Это происходит из-за отсутствия лидеров и организации, из-за того, что оно всего лишь часть стада» [Цит. по: Van Ginneken, 1992, p. 38].

Спустя почти десять лет, в 1891 году, в Италии выходит небольшая книга молодого 23летнего криминалиста Сципиона Сигеле (Scipio Sighele) «Преступная толпа». В ней автор говорит о том, что не только животные, но и люди имитируют поведение друг друга. Ранее упоминавшиеся авторы, в частности Тард, о котором речь пойдет ниже, уже предлагали этому разные объяснения: нравственная эпидемия, социальная имитация и гипнотическое внушение. Сигеле добавляет: в толпе примитивные (эмоциональные) тенденции распространяются легче, нежели цивилизованные (рациональные). Чем больше людей охвачено определенной эмоцией, тем она будет сильнее. В результате в толпе возникает некое ментальное единство, что-то вроде «души толпы».

Сигеле пишет: «Демонстрации образуются всегда меньшим числом людей, чем то, которое в конце концов принимает в них участие. В этом случае подражательное внушение

\footnotetext{
${ }^{25}$ Автор - канд. эконом. наук, доцент кафедры экономики и финансов фирмы экономического факультета ГУ ВШЭ.

${ }^{26}$ Эта книга включает три из четырех его более ранних, основополагающих статей по данной теме.
}

Выпуск \#1(13), 2010

() Электронный журнал Корпоративные Финансы, 2010 
оказывает свое влияние не только непосредственно, в том смысле, что к первой группе демонстраторов присоединяются из любопытства уличные праздношатающиеся, но и косвенным образом, в том смысле, что большинство, узнав из газет или каким-либо иным образом, что такая-то демонстрация состоится в такой-то день и в таком-то месте, скажет себе: нужно будет пойти посмотреть! - и пойдет туда на самом деле.

Таким образом, во всех сборищах - лиц, знающих истинную их цель, очень мало: большинство идет, как оно само выражается, посмотреть.

В этом и заключается психологическое условие первых моментов образования толпы; не следует, однако, полагать, что так дело продолжается долго. Мало-помалу, по мере того как демонстрация увеличивается и раздалось уже несколько криков или, если речь идет о митинге, по мере того как речи ораторов зажигают аудиторию, в разнородном агрегате толпы происходит довольно странное явление: разнородность заменяется почти совершенной однородностью. Более трусливые, видя, что дело становится серьезным, удаляются при первом удобном случае; те же, которые остались, волей-неволей доходят до одной и той же степени возбужденности: мотив, соединивший несколько первых индивидов, становится известным всем, проникает в ум каждого, и тогда толпа приобретает единодушие» [Сигеле, 1998, с. 45-46]. Согласно Сигеле, толпа всегда более эмоциональна и менее рациональна, чем отдельный человек.

«Психология толпы» ле Бона была опубликована в 1895 году. Актуальность книги не только теоретическая. 1880-1890-е годы во Франции - это время зарождения фашистских и социалистических движений. В 1894 году итальянский анархист убивает французского президента Карно, кстати, родственника ле Бона. Появляется ощущение коллапса режима. На этом фоне книга ле Бона становится интеллектуальным бестселлером.

Ле Бон, смотревший на толпу сверху вниз, отзывался о ней самым нелицеприятным образом. По его мнению, толпа неумна, неспособна к размышлению. Но эта мысль автора не является пионерской. Известный современный французский социолог Серж Московичи, автор замечательной книги «Век толп», приводит примеры еще более ранних «выходов на тему»: «...Солон утверждал, что один отдельно взятый афинянин - это хитрая лисица, но когда афиняне собираются на народные собрания в Пниксе, уже имеешь дело со стадом баранов. Фридрих Великий очень высоко ценил своих генералов, когда беседовал с каждым из них по отдельности. Но при этом говорил о них, что собранные на военный совет, они составляют не более чем кучку имбецилов. Поэт Грильпарцер утверждал: “Один в отдельности взятый человек довольно умен и понятлив; люди, собранные вместе, превращаются в дураков"» [Московичи, 1996, с. 38-39]. Вопросом, почему толпа не мыслит, задавался еще Ги де Мопассан: «Одно народное изречение гласит, - пишет он, - что толпа “не рассуждает”. Однако почему же толпа не рассуждает, в то время как каждый индивид из этой толпы, взятый в отдельности, рассуждает? Почему эта толпа стихийно совершит то, чего не совершит ни одна из ее единиц?» [Цит. по: Московичи 1996, с. 42].

Толпа восприимчива, принимает иллюзии за действительность. «Как у всех существ, неспособных к рассуждению, - пишет ле Бон, - воспроизводительная способность воображения толпы очень развита, очень деятельна и очень восприимчива к впечатлениям. Вызванные в уме толпы каким-нибудь лицом образы, представление о каком-нибудь событии или случае по своей живости почти равняются реальным образам. Толпа до некоторой степени напоминает спящего, рассудок которого временно бездействует и в уме которого возникают образы чрезвычайно живые, но эти образы скоро рассеялись бы, если бы их можно было подчинить размышлению. Для толпы, неспособной ни к размышлению, ни к рассуждению, не существует поэтому ничего невероятного, а ведь невероятное-то всегда и поражает всего сильнее» [Московичи, 1996, с. 94]. «Начиная с самой зари цивилизации, толпа постоянно подпадала под влияние иллюзий... Человек иногда повергает в прах эти иллюзии ценой ужасных переворотов, но он всегда бывает вынужден снова извлечь их из-под развалин» [Ле Бон, 1995, кн. 2, отд. 2, гл. 2]. 
Немыслящая и впечатлительная толпа легко поддается воздействию. Как позднее выразился Серж Московичи: «Человек-индивид и человек-масса - это две разные вещи, как достояние в один франк и в миллион. Эту разницу я подытожил бы одной фразой: индивида убеждают, массе внушают» [Московичи, 1996, с. 62]. На воображение толпы «очень легко действовать, в особенности образами. Такие образы не всегда имеются в нашем распоряжении, но их можно вызывать посредством умелого применения слов и формул. Искусно обработанные формулы получают действительно ту магическую силу, которая им приписывалась некогда адептами магии. Они могут возбудить в душе толпы самые грозные бури, но умеют также и успокаивать их. Можно было бы воздвигнуть пирамиду, гораздо более высокую, чем пирамида Хеопса, из костей лишь тех людей, которые пали жертвами могущества слов и формул» [Ле Бон, 1995, кн. 2, отд. 2, гл. 2 ].

По мнению ле Бона, психологические превращения индивида, включенного в группу, во всех отношениях подобны тем, которым он подвергается в гипнозе. «Коллективные состояния аналогичны гипнотическим состояниям» [Московичи, 1996, с. 116]. А в этом случае «можно получить власть над мыслями и решениями загипнотизированного заранее, на какое-то время вперед, когда гипнотизера уже не будет с ним рядом. Более того, внушенным решениям можно придать видимость добровольности. К тому же можно сделать такое внушение, когда загипнотизированный и не заподозрит вовсе, что это побуждение пришло к нему от гипнотизера» [Там же, с. 119]. «Такие отсроченные эффекты явно напоминают разные формы воздействия, наблюдаемые в обществе. Разве мы не встречаем на каждом шагу людей, безотчетно и не желая того воспроизводящих много времени спустя жесты или слова, которые они видели или слышали, считающих своими идеи, которые ктото, не спрашивая их, самым категоричным образом вдолбил им в голову? Эти эффекты, кроме всего прочего, доказывают, какое огромное множество мыслей и действий, кажущихся намеренными, осознанными и обусловленными внутренним убеждением, в действительности представляют собой автоматическое исполнение внешнего приказания» [Там же, с. 119-120].

Подобные аналогии приводят и современные экономисты, анализирующие закономерности возникновения финансовых пузырей: «Причина, по которой пузыри вводят нас в заблуждение, ровно та же, по которой нас вводят в заблуждение профессиональные иллюзионисты. Когда умные люди становятся профессионалами по обману людей и посвящают годы оттачиванию своего мастерства, они проворачивают ловкие трюки у нас на глазах и одурачивают нас, по крайней мере, на время» [Shiller, 2005, p. 76]. Но продолжим рассказ об идеях ле Бона.

Толпа опасна тем, что «душою толпы», а не только действиями правителей, порождается насилие: «Когда историки рассказывают нам, что Варфоломеевская ночь была делом короля, то они лишь указывают этим, что психология толпы им так же незнакома, как и психология королей. Подобного рода манифестации порождаются только душою толпы; самый абсолютный из монархов, самый деспотичный может только или ускорить их появление, или же замедлить их. Не короли создали Варфоломеевскую ночь, религиозные войны, и не Робеспьер, Дантон или Сен-Жюст создали террор. Во всех этих событиях действовала душа толпы, а не могущество королей» [Ле Бон, 1995, кн. 2, отд. 2, гл. 4].

По мнению ле Бона, могущество толпы пригодно только для разрушения. Закон толпы - это варварский закон. Цивилизации же создавались только узким кругом интеллектуальной аристократии, никогда - толпой. «В толпе идеи, чувства, эмоции, верования - все получает такую же могущественную силу заразы, какой обладают некоторые микробы» [Там же, кн. 2, отд. 2, гл. 3]. Как говорил Ленин, идея, овладевшая массами, становится материальной силой. Московичи расшифровывает: «Идеи управляют массами, но масса с идеями неуправляема. Чтобы решить эту насущную задачу, произвести эту алхимию, необходима определенная категория людей. Они преобразуют взгляды, основанные на чьих-то рациональных соображениях, в действие всеобщей страсти. С их помощью идея становится материальной» [Московичи, 1996, с. 163]. 
Кажется, что идеи овладевают толпой быстро, но это лишь видимость, и если так происходит, то, значит, почва подготовлена: «Действительно, некоторые идеи зачастую возникают в толпе и приводятся в исполнение с быстротой молнии, но это так лишь с первого взгляда, так как на самом деле этот взрыв всегда является результатом долгой предшествующей работы» [Ле Бон, 1995, кн. 2, отд. 2, гл. 1].

По мнению ле Бона: «...не факты сами по себе поражают народное воображение, а то, каким образом они распределяются и представляются толпе» [Там же, кн. 2, отд. 1, гл. 3]. Он фактически набрасывает концепцию эффективной пропаганды. «Идеи, - резюмирует ле Бон, - никогда не утверждаются оттого, что они точны, они утверждаются только тогда, когда с помощью двойного механизма повторения и заражения оккупировали области подсознания, где рождаются движущие силы нашего поведения. Убедить кого-либо - не значит доказать ему справедливость своих доводов, но заставить действовать в соответствии с этими доводам» [Московичи, 1996, с. 160]. Согласно ле Бону, чтобы пропаганда была эффективной, идеи должны быть: а) простыми и б) часто повторяемыми.

Поскольку толпа глупа, она не поймет слишком заумные или сложные по форме мысли: «Каковы бы ни были идеи, внушенные толпе, они могут сделаться преобладающими не иначе, как при условии быть облеченными в самую категорическую и простую форму» [Там же, кн. 2 отд. 1, гл. 3]. И «в интересах вожаков позволять себе самые невероятные преувеличения» [Там же, кн. 2, отд. 2, гл. 5]. Как выразится Московичи: «достаточно вспомнить некоторые лозунги: “Свобода или смерть”, “Да здравствует Франция”... Формулы должны быть краткими, поражающими, такими как: “Пришел, увидел, победил” Юлия Цезаря или более близкое нам “Франция проиграла сражение, но не проиграла войну” - этим призывом 18 июня 1940 года де Голль вдохновил французов, павших духом... если враг у наших границ, слова “К оружию, граждане!” звучат как сигнал горна и становятся коллективным паролем. Имея минимум смысла, но вместе с тем повелительную форму, такое слово может многое утверждать, не заботясь ни о логике, ни о правде» [Московичи, 1996, c. 187-188].

Повторяемость важна, поскольку «...часто повторяемая идея в конце концов врезается в самые глубокие области бессознательного, где именно и вырабатываются двигатели наших поступков» [Ле Бон, 1995, кн. 2, отд. 2, гл. 3]. Московичи расшифровывает: «С помощью повторения приказ, формулировка отделяются от личности вождя. Они живут собственной жизнью и обретают автономную действительность, подобно заговору или молитве. Затем они проникнут в подсознание и станут элементом коллективного верования. Этот процесс пойдет быстрее, когда толпу призовут отвечать вождю, как верующие отвечают священнику во время мессы и хором повторяют провозглашаемое слово, которое отдается громким эхом, повторяемое тысячами уст. С помощью повторения мысль отделяется от своего автора. Она превращается в очевидность, не зависящую от времени, места, личности. Она не является более выражением человека, который говорит, но становится выражением предмета, о котором он говорит. Клевещите, клевещите, что-нибудь непременно останется. Повторяйте, повторяйте, что-нибудь непременно останется, хотя бы молва. А молва, как и предрассудки, как и клевета, - это сила.

Утверждение и повторение имеют результатом коллективное внушение. Они сливаются в поток верований, которые распространяются со скоростью эпидемии. Заражение происходит тем быстрее, чем сильнее вызванные чувства и чем скорее действие соединилось, словно в коротком замыкании, с мыслью» [Московичи, 1996, с. 191-192].

Кроме того, «повторение имеет двоякую функцию: будучи навязчивой идеей, оно также становится барьером против отличающихся или противоположных мнений. Таким образом, оно сводит к минимуму рассуждения и быстро превращает мысль в действие, на которое у массы уже сформировался условный рефлекс, как у знаменитых собак Павлова» [Московичи, 1996, с. 190].

Раз толпа ведома, возникают и вожди (свято место пусто не бывает). Но чтобы зажечь толпу, вожак сам должен быть увлечен идеей: «Вожак обыкновенно сначала сам был в числе 
тех, кого ведут; он так же был загипнотизирован идеей, апостолом которой сделался впоследствии» [Ле Бон, 1995, кн. 2, отд. 2, гл. 3]. «Великие фанатики, увлекавшие душу толпы... только тогда подчинили ее своему обаянию, когда сами подпали под обаяние известной идеи. Тогда им удалось создать в душе толпы ту грозную силу, которая называется верой и содействует превращению человека в абсолютного раба своей мечты» [Там же, кн. 2, отд. 2, гл. 3]. Сравните у Московичи: «Сектантский фанатизм исходит от вождя, и любой великий вождь - фанатик. Массы заражаются фанатизмом с поразительной легкостью. Несокрушимая уверенность в себе фанатиков порождает безмерное доверие других. Они говорят себе: “Он знает, куда идет, тогда пойдем туда, куда он знает”» [Московичи, 1996, с. 164]. Не всякий подходит на роль вожака. Толпа подчиняется вождю, пока боготворит его: «...для толпы надо быть богом или ничем» [Ле Бон, 1995, кн. 2, отд. 1, гл. 4].

Развивая идеи ле Бона, современные социологи говорят о том, что мы испытываем потребность в «погоне за экспертом» [Larrick, Soll, 2003]. Возникает теория «пророков и простаков»: «Сколько бы ни доказывали, что пророков на свете не бывает, простаки всегда будут расплачиваться за их мнимое существование» [Armstrong, 1980].

Суть теории ле Бона блестяще суммировал Московичи. По его мнению, первый, лебоновский вариант психологии толп содержит следующие значительные идеи: «Толпа в психологическом смысле является человеческой совокупностью, обладающей психической общностью... Индивид действует, как и масса, но первый - сознательно, а вторая неосознанно... Толпы консервативны, несмотря на их революционный образ действий. Они всегда кончают восстановлением того, что они низвергали... Массы, каковы бы ни были их культура, доктрина или социальное положение, нуждаются в поддержке вождя. Он не убеждает их с помощью доводов рассудка, не добивается подчинения силой. Он пленяет их, как гипнотизер, своим авторитетом. Пропаганда (или коммуникация) имеет иррациональную основу, коллективные убеждения и инструмент - внушение... Критический ум, отсутствие убежденности и страсти являются двумя препятствиями к действию. Внушение может их преодолеть, именно поэтому пропаганда, адресованная массам, должна использовать язык аллегорий - энергичный и образный, с простыми и повелительными формулировками. Политика, целью которой является управление массами (партией, классом, нацией)... должна опираться на какую-то высшую идею (революции, родины), даже своего рода идеюфикс, которую внедряют и взращивают в сознании каждого человека-массы, пока не внушат ее. Впоследствии она превращается в коллективные образы и действия» [Московичи, 1996, c. 128-129].

Габриэль Тард - второй патриарх психологии толп - был провинциальным судьей и, как Сигеле, криминалистом. В 1892-1893 и 1898-1899 годах он публикует четыре статьи, посвященные психологии толпы. Тард задается вопросом о том, как формируется толпа. «Каким таким волшебным способом так много людей - когда-то разобщенных и безучастных по отношению друг к другу - порождают солидарность, объединяются в намагниченную цепочку, выкрикивают одно и то же, бегут в одном направлении и действуют согласованно?» Его ответ: «В результате симпатии, источника подражания и жизненного принципа социальных тел» [Цит. по: Van Ginneken, 1992, p. 193].

Подражание - это ключевая идея Тарда. Как позже сформулирует Московичи: «в большинстве случаев мы предпочитаем один объект другому потому, что один из наших друзей уже его предпочитает, или потому, что предпочтение представляет заметное социальное значение. Как и дети, взрослые, когда они голодны, ищут те продукты, которые ищут другие. В своих любовных связях они ищут женщину или мужчину, которых любят другие. Они отвергают того или ту, кто нелюбим. Когда говорят о мужчине или женщине, что они желанны, это значит, что другие их желают. Не потому, что они одарены каким-то особым качеством, а потому, что они отвечают образцу, соответствуют моде этого момента... мы имеем те же вкусы, любим те же вещи и тех же людей. Мы ждем, чтобы нам сказали, что нужно ценить или любить, чтобы желать и приобретать эти предметы - 
большие американские машины или маленькие английские, отпуск у моря или в горах, стройных женщин или дородных и т.п.» [Московичи, 1996, с. 315, 317]. На идеях Тарда о подражании строится «Теория праздного класса» Торстейна Веблена.

Тард различает рождение новых идей (инновацию) и их копирование - подражание или имитацию. Некоторые люди охотно подражают, а некоторые сопротивляются нововведениям. Для социума характерно и распространение нового (мода), и консервация устоев (традиция). Распространение инноваций зависит и от объективных причин, например их практической значимости, и от субъективных - психологических и социальных. Так, инновацию скорее воспримут те, кто находится ближе к источнику, имитировать поведение «сильных мира сего» (или, как сказали бы сейчас, звезд) будут охотнее, чем простых смертных.

Московичи так суммировал суть идей Тарда насчет инновации и имитации: «Человек, который изобретает, нарушает порядок вещей. Человек, который подражает, его восстанавливает. Первый совершил последовательные изменения, то есть эволюцию, второй - повторяющиеся монотонности, короче говоря, традицию, моду.

Другими словами, в недрах каждого дремлет овечья натура, заставляющая избегать страданий и риска изобретателя и просто с наименьшими затратами воспроизводить изобретение, которое потребовало значительной энергии. Понятно, что существа податливые позволяют себя увлечь кем угодно, если тот желает ими руководить. Он их гипнотизирует помимо прочего своим авторитетом. Само общество создает гипнотическую среду, сферу отпущенных на свободу образов и автоматизмов. Оно погружено в атмосферу иллюзий, которые история сохранила в своей памяти».

«Общественное состояние, - утверждает Тард, резюмируя свою концепцию, - как и состояние гипнотическое, - это не более чем разновидность сна: сон управляемый и сон под воздействием. Иметь лишь внушенные идеи и считать их спонтанными - вот иллюзия, свойственная сомнамбуле и точно так же общественному человеку». С помощью этих захватывающих сопоставлений Тард напоминает нам, что человек - это, вне всякого сомнения, социальное животное. Но он является таковым тогда и только тогда, когда он внушаем. Конформизм - вот первое социальное качество, создающее основу внушаемости ... Он объединяет людей и погружает их в туманный мир сновидений. Они подражают, подобно автоматам, они подчиняются, как сомнамбулы. И все вместе растворяются в огромном людском море» [Цит. по: Московичи, 1996, с. 203-204].

Как и его предшественники, Тард говорит о том, что в толпе подавляются высшие и разрастаются низшие инстинкты. Он задается вопросом «почему?», но ответ ищет не столько во взаимном влиянии однородных людей друг на друга, сколько во влиянии тех, кто ведет, на тех, кого ведут. Ведущие зачаровывают ведомых своим обаянием. «Сколько великих людей, от Рамзеса до Александра, от Александра до Магомета, от Магомета до Наполеона, овладели таким образом народным духом! Сколько раз продолжительная фиксация такой блестящей точки, как человеческий гений или слава, заставляли впадать в каталепсию целые народы» [Цит. по: Сигеле, 1998, с. 50-51].

Тард был первым, кто заговорил о таком явлении, как общественное мнение. Возникновение общественного мнения, то есть мнения широких слоев населения, связано с развитием массовых средств информации. В описываемый период оно представляло собой широкое распространение газет. Именно газеты становятся выразителями общественного мнения.

Вот как Московичи продолжает мысль Тарда о роли прессы в формировании общественного мнения: «С наступлением массового общества пресса становится первейшей основой мнений, которые распространяются мгновенно и без посредников во все уголки страны, даже по всему миру. Отчасти заменив разговор, она в какой-то степени господствует над ним. Пресса не непосредственно создает свою публику и влияет на нее, а именно посредством бесед, которые она стимулирует и порабощает, чтобы сделать их резонаторами. Вот как об этом говорит Тард: “Достаточно одного пера, чтобы привести в движение 
миллионы языков”» [Московичи, 1996, p. 238]. «Тард превращает коммуникацию в разновидность внушения и сближает деятельность журналиста с воздействием гипнотизера... он вводит в психологию толп... быстро расширяющуюся область явлений коммуникации» [Там же, р. 201]. Ту роль, которую во времена Тарда в формировании общественного мнения играла пресса, в наше время исполняют радио и телевидение.

По мнению Джаапа ван Гиннекена, одного из ведущих современных исследователей развития психологии толпы, на блестящую книгу которого «Толпы, психология и политика, 1871-1899» я в этой статье ссылаюсь, ранние исследования психологии толпы ле Бона, Тарда и других породили две линии в современной психологии. Первая - та, которая выросла из ле Бона, - занимается деиндивидуализацией индивида в группе (толпе). Она представлена Леоном Фестингером, о взглядах которого мы будем подробнее говорить в следующей статье. Вторая линия - та, которая выросла из Тарда, - изучает общественное мнение, теорию массовых коммуникаций, массовую культуру. Первая имеет большую объяснительную силу для «толп», которые физически собираются вместе, вторая - для рассеянных групп типа общественных движений. (Я же полагаю, что идеи Фестингера применимы для рассеянных групп в той же мере, что и для собравшихся под одной крышей. Но об этом позже.) Закончим на этом разговор о ранних теориях психологии толпы и посмотрим, как эти идеи преломляются для ситуации на финансовых рынках.

Законы манипуляции мнением толпы, о которых говорили Тард и ле Бон, никуда не делись и в наше время и в полной мере применимы для манипулирования инвестораминепрофессионалами при принятии ими решений. Как пишет известный управляющий активами Марк Фабер, «жизнь инвестиционной мании может поддерживаться гораздо больше, чем можно было бы подумать, умной пропагандой, которая нацелена на подогревание “энтузиазма” и “интереса” инвестирующей публики» [Faber, 2008, p. 142].

Роберт Шиллер в своем бестселлере «Иррациональное возбуждение» приводит многочисленные свидетельства того, что средства массовой информации действуют по канонам этого жанра. В частности, со ссылкой на исследование Джеймса Гамильтона он отмечает, что «на американском телевидении в течение последних десятилетий в вечерних новостях сокращается количество серьезных новостей, которые замещаются либо историями, либо практически полезными для зрителя новостями». Гамильтон связывает это c растущей конкуренцией внутри новостного медийного бизнеса, конкурентное преимущество которого во все большей степени зависит от привлечения и сохранения маргинальных клиентов, которые не заинтересованы в глубине понимания» [Shiller, 2005, p. 44].

Похожие мысли есть и у Фабера: «Роль CNBC может быть понята в свете взглядов Гитлера об интеллектуальном уровне пропаганды. По Гитлеру, пропаганда должна быть нацелена на интеллект самых необразованных людей толпы, и чем шире массы, тем ниже должен быть уровень. CNBC, чьи прибыли зависят от количества зрителей, которых он может привлечь, должен любой ценой поддерживать интерес инвесторов к покупке и владению акциями, а также взращивать интерес публики к финансовым рынкам при помощи разного рода “хороших новостей”» [Faber, 2008, p. 142-143].

Со ссылками на другие источники журналист Джеймс Шуровьески отмечает, что «во время наибольшего подъема на рынке выпуски СNBC смотрели семь миллионов человек, и, если вас вообще интересовал фондовый рынок, это было неизбежно... CNBC был повсюду: операционный зал биржи и брокерские помещения - это само собой, но это и оздоровительные клубы, рестораны, цветочные магазины, нефтяные вышки, заводы, студенческие общежития, комнаты присяжных и тюрьмы.

CNBC обеспечивал круглосуточное освещение ситуации на рынке, постоянную бегущую строку с биржевыми курсами внизу экрана и регулярно поступающие последние новости с разных фондовых бирж. В определенном смысле телеканал был всего лишь вестником, позволявшим участникам рынка общаться друг с другом. Но по мере роста популярности CNBC возрастало и его влияние. Вместо обычных комментариев о состоянии 
рынков он начал (невольно) манипулировать ими. Не важно, что говорится на CNBC, после чего люди начинают активно покупать и продавать те или иные акции, - важен сам факт, что это говорится именно на CNBC» [Шуровьески, 2007, с. 242].

CNBC усугубила зависимый характер фондового рынка, поскольку бомбардировала инвесторов новостями о том, что думают другие инвесторы. До появления CNBC почти все свои сведения о коллегах инвесторы получали из сводок биржевого телеграфа. Поэтому, когда вы пытались угадать мотивы остальных участников торгов, между вами и рынком существовала некоторая дистанция. В новом мире доступных финансовых новостей ваши рассуждения более не нужны или даже невозможны. Вместо этого вам постоянно твердят о том, что говорят трейдеры и как чувствует себя рынок. Если вернуться к метафоре Кейнса ${ }^{27}$, можно сказать, что CNBC целыми днями вещает о том, что говорят абсолютно все по поводу того, какие девушки являются самыми красивыми. Это усложняет и без того трудную задачу отдельного инвестора прийти к независимому суждению о том, какая девушка краше всех остальных. Очевидно, это становится особенно важным аспектом в те моменты, когда инвесторы проявляют стадное чувство. Например, в тот день, когда рынок резко падает, CNBC помещает на экране яркую надпись MANIAC MONDAY (“Безумный понедельник”), и каждое решение инвестора диктуется паникой, знак которой он видит на телеэкране перед собой. Все думают об одном, ибо трудно думать о чем-то ином, нежели о том, что делают другие» [Шуровьески, 2007, с. 242-243].

Факты подтверждают, что для CNBC границы приличий не существовали. Вот пример из книги «Анти-Гринспен»: «Может ли цена акций когда-нибудь достигнуть слишком высокого уровня? Пузыревидение (Bubblevision [CNBC]) обсуждало, что Cisco может быть первой компанией, чья капитализация достигнет триллиона. Ну, при этой мании может случиться все (в этот момент капитализация Сisco составляла примерно 500 млн долларов. E.Ч.). Но, ребята, весь мировой ВВП - только 30 трлн долларов. Может ли компания с выручкой в 12 млрд - или даже 15 или 20 млрд - в действительности стоить триллион, 3\% мирового ВВП? ВВП США - только 9 трлн долларов, так может ли одна компания с выручкой такого размера стоить $1 / 10$ экономики США?» ${ }^{28,} 29$ [Fleckenstein, 2008, p. 86].

В 1970-1980-е годы роль СNBC выполнял популярный журнал Мопеу, посвященный инвестированию денег, подписка на который измерялась сотнями тысяч копий. «Как превратить 50 тыс. долларов в 250 тыс. долларов всего за пять лет», «Как начать инвестировать... и делать это правильно», «Новые миллионеры» - таковы были заголовки журнала, предполагавшие, что любой американец, начав инвестировать, может разбогатеть. «У нас было много чрезмерных упрощений», «меня беспокоило, что инвестирование выглядело более простым, чем оно было на самом деле», «нам не позволялось писать негатив», «журнал избегал говорить о некоторых отрицательных моментах персонального инвестирования», «журнал делал вид, что предлагал что-то дельное, а на самом деле расфуфыренную пустышку» - так отзывались о происходившем сами журналисты [Nocera, 2004, p. 282].

\footnotetext{
27 Речь идет о знаменитой метафоре Кейнса из «Общей теории занятости, процента и денег», в которой он сравнил биржевые торги с конкурсами красоты: «Профессиональное инвестирование похоже на эти конкурсы в газетах, когда участникам предлагается выбрать шесть самых хорошеньких мордашек из сотен фотографий, а приз присуждается тому, чей выбор как можно точнее совпал с предпочтениями всех остальных участников. Поэтому ему надо выбирать не те лица, которые он считает самыми хорошенькими, но те, которые, по его мнению, более всего придутся по вкусу всем остальным участникам. Выходит, что каждый участник решает проблему с той же точки зрения, что и другие» [Цит. по: Шуровьески, 2007, с. 238].

28 Последняя постановка не корректна. Правильнее было бы сказать «оцениваться в сумму, равную одной десятой ВВП». Но общая идея рассуждений верна.

29 Кроме того, не все так просто, как пытается представить Флекенштейн. Как отмечает Шуровьески, «люди, покупавшие акции Cisco, когда они были самыми дорогими в мире, несомненно, поступали так, веря в то, что акции этой компании будут расти и впредь. Но эта вера взошла из идеи, что Cisco действительно могла стоить 500 млрд долл.». Действительно, почему компания, которая по факту стоит 500 млрд, не может стоить 1 трлн? Как выразился Марк Фабер, «никакая цена не является слишком высокой для быка» [Faber, 2008, p. 77].
}

Выпуск \#1(13), 2010

(C) Электронный журнал Корпоративные Финансы, 2010 
Как говорит Шиллер, «реклама - по большей части это не представление важных качеств продукта, а простое напоминание о продукте и его образе. С учетом того факта, что средства массовой информации уделяют все большее внимание теме инвестиций, бум на фондовом рынке должен являться не большим сюрпризом, чем рост продаж последней модели спортивного автомобиля после массированной рекламной кампании» [Shiller, 2005, p. 44]. Приемами эффективной пропаганды пользуются и продавцы акций: «Те, кто продает акции публике, обычно рассказывают об акциях историю, живенькую историю о компании, сущности ее продукта, и о том, как публика использует этот продукт. Специалисты по продажам нечасто начинают рассуждать о вероятностях или других цифрах, или о том, является ли цена справедливой в сопоставлении с будущими дивидендами и денежными потоками» [Shiller, 2001, p. 150].

Шиллер также отмечает, что «одна из причин того, почему фондовый рынок США так влияет на другие рынки, кроется в английском языке, который стал мировым языком» [Shiller. 2005, p. 104].

В полном смысле применима к надуванию финансовых пузырей и идея о вожаке стаи (или баране-провокаторе?). Марк Фабер высказывает весьма оригинальный взгляд на роль лидера в развитии мании. Он, отталкиваясь от Фрейда, считает, что первичные лидеры финансового рынка - это идеи, а несущие их индивиды - вторичные лидеры: «Из-за сильной привязанности толпы к лидеру потеря лидера или потеря престижа лидера обычно ведет к панике. Фрейд... объясняет, что толпа может быть движима и идеями, а люди, которые их представляют, становятся “вторичными лидерами”» [Faber, 2008, p. 139]. Сравните это утверждение с мыслью известного американского управляющего деньгами, сторонника концепции стоимостного инвестирования Дэвида Дремана о том, что первым условием финансовой спекуляции является «создание образа бесконечного богатства», вокруг которого собирается толпа [Dreman, 1998, p. 370]. Примерно то же самое имеет в ввиду и Роджер Ловенштейн, известный американский финансовый журналист, когда утверждает, что «падение Enron было отражением его подпорченного имиджа» [Lowenstein, 2004, p. 181].

Кажется, что так и происходит во время инвестиционных маний. Идея «больших прибылей» - движущая сила мании, а лидеры корпораций, успешные инвесторы, главы центробанков, министры финансов и спекулянты, которые наслаждаются большим престижем, о которых пишут в журналах и интервью с которыми показывают по телевидению, являются «вторичными “лидерами”» [Faber, 2008, p. 139]. Пожалуй, не ошибусь, если скажу, что на роль «вожака стаи» в последние годы больше всех претендует Алан Гринспен. Он сделался фигурой, вызывавшей полное доверие инвесторов, которые думали, что при Гринспене с рынками ничего не случится. Кстати, Фабер еще в 2001 году предсказал, что на вере в Гринспена инвесторы потеряют [Там же, p. 250].

Как пишет известная американская финансовая журналистка Мегги Махар, «большинство инвесторов получали инвестиционные советы из средств массовой информации, и они предпочитали верить, что Эбби Коэн (Abby Cohen), Мэри Миккер (Mary Meeker), Генри Блоджет (Henry Blodget) и даже Бартон Биггз (Barton Biggs)... ${ }^{30}$ говорили прямо для них. По большому счету, финансовая пресса ничего не сделала для того, чтобы рассеять эту иллюзию. Средства массовой информации нуждались в гуру - они придавали финансовым новостям колорит и убедительность. Они делали их волнующими. Они делали их актуальными. Они делали их новостями» [Mahar, 2004, p. 300].

Шиллер, со ссылкой на знаменитые эксперименты американских психологов Эша (Asch) и Милгрема (Milgram), объясняет, что авторитеры способствуют синдрому чрезмерной уверенности инвестора со всеми вытекающими отсюда последствиями: «Люди

\footnotetext{
${ }^{30}$ Ведущие аналитики банков Goldman Sach, Morgan Stanley, Merrill Lynch и снова Morgan Stanley (Микер была главной по интернет-акциям, а Бигз - главным глобальным стратегом). Блоджет впоследствии был осужден за предоставление инвесторам заведомо ложной информации, ибо была найдена его частная переписка, в которой он открыто говорил о том, какую дрянь банк впихивает инвесторам. Другие аналитики были более осторожными.
}

Выпуск \#1(13), 2010

(C) Электронный журнал Корпоративные Финансы, 2010 
полагаются на авторитеты при выработке своих собственных мнений. Потом, сильно уверовав и в свои мнения, переносят уверенность в авторитетах на уверенность в своих мнениях» [Shiller, 2005, p. 159].

Рассуждений психологов для объяснения стадного поведения на рынке будет мало. В следующей статье мы расскажем о том, что к этому добавляют социология и экономика.

\section{Список литературы}

1. Ле Бон Г. Психология народов и масс. С.-Пб., Макет, 1995.

2. Московичи С. Век толп. М.: Центр психологии и психотерапии, 1996.

3. Сигеле С. Преступная толпа. Опыт коллективной психологии. М: КСП, 1998.

4. Шуровьески Д. Мудрость толпы. Почему вместе мы умнее, чем поодиночке, и как коллективный разум формирует бизнес, экономику, общество и государство. Киев: Вильямс, 2007.

5. Armstrong, S. (1980), The Seer-Sucker Theory: The Value of Experts in Forecasting, Technological Review, 83 (1980).

6. Faber, M. (2008), Tomorrow's Gold. Asia's Age of Discovery. - Hong Kong: CLSA Books.

7. Fleckenstein, W., and Sheehan, F. (2008), Greenspan's Bubbles: The Age of Ignorance at the Federal Reserve. - N.-Y.: McGraw-Hill.

8. Larrick, R., and Soll, J. (2003), Intuitions about Combining Opinions: Misappreciation of the Averaging Principle, INSEAD Working Paper, 2003.

9. Lowenstein, R. (2004), Origins of the Crash. - N.-Y.: The Penguin Press.

10. Mahar, M. (2004), Bull! A History of the Boom and Bust. - N.-Y.: Harper Collins Publishers.

11. Nocera, J. (2004), A Piece of The Action. How the Middle Class Joined the Money Class. N.-Y.: Simon and Schuster.

12. Shiller, R. (2005), Irrational Exuberance. - N.-Y.: Brodway Books.

13. Van Ginneken, J. (1992), Crowds, Psychology and Politics, 1871-1899. - Cambridge: Cambridge University Press. 